\title{
Defect Prediction For Assembled Products: A Novel Model Based On The Structural Complexity Paradigm
}

\section{Elisa Verna}

Politecnico di Torino

\section{Gianfranco Genta}

Politecnico di Torino

\section{Maurizio Galetto}

Politecnico di Torino

Fiorenzo Franceschini ( $\nabla$ fiorenzo.franceschini@polito.it )

Politecnico di Torino https://orcid.org/0000-0001-7131-4419

\section{Research Article}

Keywords: Defect prediction, Assembly, Complexity, Low-volume production, Product design

Posted Date: August 18th, 2021

DOI: https://doi.org/10.21203/rs.3.rs-792386/v1

License: (a) (i) This work is licensed under a Creative Commons Attribution 4.0 International License. Read Full License

Version of Record: A version of this preprint was published at The International Journal of Advanced Manufacturing Technology on March 4th, 2022. See the published version at https://doi.org/10.1007/s00170-022-08942-6. 


\title{
Defect prediction for assembled products: a novel model based on the structural complexity paradigm
}

\author{
Elisa Verna, Gianfranco Genta, Maurizio Galetto, Fiorenzo Franceschini* \\ Politecnico di Torino, \\ Department of Management and Production Engineering, \\ Corso Duca degli Abruzzi 24, 10129 Torino, Italy, \\ *Corresponding author (mail fiorenzo.franceschini@polito.it)
}

\begin{abstract}
Increased assembly complexity is one of the main challenges in manufacturing. Complexity can induce increased assembly cost and time, operational issues, costly defects and quality losses. Several approaches have been proposed in the literature to predict product defects by using assembly complexity as predictor. Despite defect prediction is of utmost importance from the early stages of product and related quality inspection design, most approaches are not directly applicable because they rely on the operators' prior subjective knowledge and are designed for specific industrial applications. To overcome this issue, the present research proposes a novel approach to predict product defects from a more objective evaluation of complexity. This is one of the first attempts to predict product defects and improve its quality with a purely objective assessment of the complexity of the assembled product, without the need for operators' evaluations and assembly experience. Defect rates in the model are predicted by using a recent conceptual paradigm of complexity that considers only structural properties of assembly parts and their architectural structure. The novel model is applied to a real assembly process in the electromechanical field and is compared with one of the most accredited in the literature, i.e. the Shibata-Su model. Empirical results show that, despite the super-linear relationship between defect rates and complexity in both models, the objective approach used in the novel model leads to more accurate and precise predictions of defectiveness rates, as it does not include the variability introduced by operators' subjective assessments. Adopting this novel model can effectively improve the estimate of product defects and support designers' decisions for assembly quality-oriented design and optimization, especially in early design phases.
\end{abstract}

Keywords: Defect prediction, Assembly, Complexity, Low-volume production, Product design. 


\section{NOMENCLATURE}

$C f_{P, i}$ Process-based complexity factor of workstation $i$

$S S T_{i j}$ Sony Standard Time spent on the job element $j$ in the workstation $i$

$t_{0}$ Threshold assembly time, i.e. the time required to perform the simplest assembly operation

$N_{a, i}$ Number of job elements in the workstation $i$

$T A T_{i}$ Total assembly time related to the workstation $i$

$C f_{D, i}$ Design-based complexity factor of workstation $i$

$w_{q}$ Weight of parameter $q$

$a_{q r}$ Relative importance of parameter $q$ over parameter $r$

$l$ Total number of parameters

$D_{k q i}$ Degree of difficulty of the parameter $q$ in the workstation $i$ estimated by the expert $k$

$C_{i}$ Assembly complexity of workstation $i$

$C_{1, i}$ Part complexity in workstation $i$

$C_{2, i}$ Connection complexity in workstation $i$

$C_{3, i}$ Topological complexity in workstation $i$

$\gamma_{p i}$ Handling complexity of part $p$ in workstation $i$

$N_{i}$ Total number of product parts in workstation $i$

$\varphi_{\text {pri }}$ Insertion complexity of part $p$ to $r$ in workstation $i$

$A_{\text {pri }}$ Connectivity between parts $p$ and $r$ in workstation $i$

$E_{A i}$ Matrix energy (or graph energy) of the adjacency matrix related to the workstation $i$

$\delta_{p i} p^{\text {th }}$ singular value of the adjacency matrix of the product assembled in the workstation $i$

$N_{S i}$ Total number of singular values of the product connectivity matrix related to workstation $i$

WS Workstation

$D P U_{i}$ Defects per unit in the workstation $i$

$S$ Standard error of the regression

\section{INTRODUCTION}

Global competition in manufacturing has forced many companies to improve and diversify their product range, increasing the number of product variants and their fabrication options. This has inevitably led to increased product and manufacturing complexity [1, 2]. In manual assembly, the complexity of the assembly process is a fundamental driver affecting the usability of the equipment, the acquisition of dynamic skills, operation safety and human performance [3]. As a result, if 
assembly complexity is not managed adequately at early stages of process planning, it can lead to increased assembly time and errors and reduce assembly quality [4-7].

In the literature, assembly complexity is often linked to the physical attributes of the products to be assembled, e.g. in Design for Assembly (DFA) or Hitachi Assembly Evaluation Method (AEM) [8, 9]. It is also associated with both product variety and assembly process information. In this case, the complexity is defined as "operator choice complexity" [10]. A second set of approaches evaluates the complexity of assembly and analyzes the cause-effect relationship between task parameters and assembly errors through statistical methods [11, 12]. Furthermore, a third set of methods uses information about system components (e.g., the number of flow paths and travel distance) and system elements (e.g., the number of components, setup time, cycle time and reliability) to measure sources of task or system complexity [13-15]. Apart from the objective characteristics, complexity is also affected by the context and the observer [16]. This subjective nature has prompted some authors to evaluate it based on interviews and questionnaires [17-21].

A growing number of studies linked product complexity with defects occurring in the manual assembly [6, 11, 20, 22-27]. Although these predictions models play a crucial role in improving the quality of product and production process of companies in various industrial contexts, most of them present some criticalities. First of all, in some cases, the methodology used to evaluate assembly complexity is designed for the specific industrial application, such as in the studies of Hinckley [11] and Shibata [22], where the methods proposed were suitable for semiconductors and audio equipment, respectively. Besides, a second limit of published research can be found in the subjectivity of some approaches used to evaluate assembly complexity. As demonstrated in the study of Alkan [4], perceived complexity does not correspond precisely to product complexity because operators start to perceive the assembly operations as complex when the product complexity reaches a stagnation point.

Therefore, the two above mentioned limitations of the approaches typically used for defect prediction, i.e. the need for subjective evaluations of the operators based on their assembly previous experience, and the dependence on the specific industrial application, make their applicability in the early stages of product design and related quality control not so straightforward. To overcome these issues, the present paper aims to develop a novel approach to predict assembly defects in manufacturing by adopting a different paradigm of complexity that uses only an objective perspective and does not depend on the application field. In detail, the structural complexity paradigm proposed by Alkan [4] and Sinha [28] is adopted as the predictor of the model. Such complexity is evaluated considering structural properties associated with handling and insertion of assembly parts and their architectural structure [4]. Depending solely on physical design information, this approach can be considered more practical from the design point of view, especially in the early design stages, when real production 
data or the physical mockup are not available. Two are the Research Questions (RQ) addressed in this paper:

RQ1: Is there a relationship between product defects and its structural complexity?

RQ2: How much does the use of different methods to assess product complexity affect the prediction of defects?

In order to answer these questions, a novel defect prediction model based on the structural complexity paradigm is developed, using a low-volume production of wrapping machines as a case study. The novel model is then compared with one of the most accredited in the literature, i.e. the Shibata-Su model, that was successfully implemented in previous studies [20, 22, 25, 27, 29]. In this approach, complexity is divided into a process-based and a design-based complexity, according to the studies of Shibata [22] and Su [20]. Empirical results showed that the novel defect prediction model allows for more accurate and precise estimates of defectiveness rates with respect to the Shibata-Su model. The authors believe that the novel approach based on the structural complexity paradigm can better support designers in the assembly quality-oriented design and optimization process. Furthermore, the novel prediction model can effectively help designers to get reliable defect estimates at early design stages and support decisions in the planning of quality inspections [29-31]. Besides, by providing new insights into defects prediction, the present research should make a useful contribution to the field of low-volume production, where the inadequacy of traditional statistical approaches make quality control and inspection planning challenging [27, 29, 31-34].

The rest of the paper is arranged as follows. In Section 2, the conceptual background is presented, including a brief review of assembly complexity criteria and defect prediction models in the literature. Section 3 describes the novel defect prediction model that uses as predictor the structural complexity paradigm. In Section 4, the novel model is applied to the assembly process of wrapping machines and compared with the Shibata-Su model. Finally, Section 5 concludes the paper.

\section{CONCEPTUAL BACKGROUND}

\subsection{ASSEMBLY COMPLEXITY PARADIGMS}

The scientific literature proposes different approaches to assess assembly complexity, based on the product to be assembled or the process sequence for the assembly [35]. Several methods are built upon the concept of easy of assembly, e.g. Design for Assembly and Manufacture (DFMA) [8, 9]. Such approaches aim at enhancing the product design by reducing part numbers, optimizing part handling and insertion attributes, penalizing inefficient design [35].

Moreover, a growing body of literature provides an assessment of assembly complexity by using different design complexity criteria and time estimation methodologies [11, 20, 22, 35]. Hinckley 
[11] defined an assembly complexity factor based on the Westinghouse DFA worksheet suggesting a theoretical time required to assemble a product. Shibata [22] proposed to evaluate process complexity based on the method of Sony Standard Time (SST) and design complexity through the design for assembly/disassembly Cost-effectiveness (DAC) method. Although these approaches provide a robust assessment of assembly complexity, the methodologies used are designed for specific assembly products. For instance, Hinckley (1994) based his study on the Westinghouse Database, specifically designed for semiconductor products. Moreover, the DAC method used by Shibata as a measure of design assemblability is a Sony's methodology specific for audio equipment. Therefore, in order to extend the methodologies proposed by these authors to other contexts, it is necessary to adapt them to the specific case study, either by slightly modifying them or by identifying more suitable approaches.

Further approaches consider physical and cognitive elements to calculate the relative effort of each manufacturing task to define an "operational complexity index" [13]. Such an index is designed as a function of the quantity and diversity of both product and process elements and the relative complexity coefficient. In a later study, Samy and ElMaraghy [15] extended the approach mentioned above by adding DFA criteria to evaluate the assembly complexity of individual product parts. Besides, Richardson et al. [36] proposed a practical model to predict the difficulty of assembly of an object based on its physical attributes. However, this approach is dependent on the specific application it is developed for, and, therefore, requires further efforts to produce a more general model.

Extensive research has shown that complexity may have a subjective nature and depend on the specific context and operator who perceives it [37]. Accordingly, survey-based methods are often adopted to assess the perceived level of complexity arising from human-system interactions and manufacturing systems $[17,19,24]$.

Recent studies tried to overcome the above restrictions (specific industrial domain and applications, subjective elements, etc.) proposing a method based on structural complexity that allows supporting early design phases of assembly products [4, 28, 35, 38].

\subsection{DEFECT PREDICTION MODELS}

A growing number of studies adopted the assembly complexity to predict the occurrence of defects in the final product $[6,11,20,22-27]$.

In the electromechanical assembly, Shibata [22] proposed a power-law defect-rate prediction model based on two factors, i.e. process and design based complexity factors. Su et al. [20] developed a new defect model to match the characteristics of copier assembly. Besides, Antani [23] successfully tested that manufacturing complexity can be used to predict product quality reliably. By focusing on mixed- 
model automotive assembly, manufacturing complexity was estimated incorporating variables driven by design, process and human factors [23]. In later studies, Krugh et al. [6, 39] adapted the approach proposed by Antani to be implemented with automotive electromechanical connections in a large complex system. Falck et al. [24] designed a tool to predict and control operator-induced quality errors by developing a method for predictive assessment of the complexity of manual assembly. As mentioned, the application fields of these models are multiple, ranging from the electromechanical to the automotive sector. The identification of suitable defect prediction models for such industrial domains and applications is a crucial factor for practical assistance in the design, improvement and optimization of assembly quality [20]. Furthermore, the adoption of reliable estimates of defect rate can successfully help inspection designers in the inspection process planning, also in the early design phase $[30,32,40]$.

\subsubsection{PROCESS AND DESIGN BASED COMPLEXITY MODEL (SHIBATA-SU MODEL)}

This section reviews one of the most accredited prediction models developed in the literature, i.e., the Shibata-Su model. Such a model combines the approaches developed by Shibata [22] and Su et al. [20] and has also been successfully implemented in recent studies by the authors [25, 27, 29, 41].

According to Shibata [22], a series of process steps, or workstations, defined through sheets of operation standards compose the product assembly process. Furthermore, a certain number of job elements, i.e. elementary operations, is performed in each workstation [22,42]. The job elements are the minimum components of a specific task, and should have easily identifiable starting and stopping points and be repeatable regularly throughout the workday. To predict the process complexity, Shibata defined a process-based complexity factor for each workstation, as follows:

$$
C f_{P, i}=\sum_{j=1}^{N_{a, i}} S S T_{i j}-t_{0} \cdot N_{a, i}=T A T_{i}-t_{0} \cdot N_{a, i}
$$

where:

- $\quad$ the index $i$ refers to the generic $i$-th workstation $(i=1, \ldots, m)$;

- $\quad N_{a, i}$ is the number of job elements in the workstation $i$;

- $S S T_{i j}$ is the Sony Standard Time spent on the job element $j$ in the workstation $i$;

- $\quad T A T_{i}$ is the total assembly time related to the workstation $i$;

- $t_{0}$ is the threshold assembly time, i.e. the time required to perform the most straightforward assembly operation, below which neither assembly operations nor assembly defects exist [22]. 
It is worth noting that the assembly times $S S T_{i j}$ are evaluated according to the Sony Standard Time (SST), a commonly used time estimation tool for electronic products. Thus, these are the standard times in which the operators should complete each job element and not the actual assembly times.

Since $C f_{P, i}$ is a time-related measure, Shibata [22] claimed that it may not capture all the sources of defects. For this reason, he introduced a second predictor, a design-based assembly complexity factor [22]. Such a design factor was defined as the ratio between a calibration coefficient and the ease of assembly (EOA) coefficient of each workstation, estimated through the assembly/disassembly costeffectiveness (DAC) method developed in Sony Corporation [43].

In a subsequent study, Su et al. [20] remarked that the DAC method, which was developed specifically for Sony electronic products, may not be directly suitable for other types of products, such as electromechanical products. Therefore, he proposed a different method to evaluate the design complexity to cope with this issue [20]. The methodology developed by $\mathrm{Su}$ et al. [20] relies on the approach developed by Ben-Arieh to assess the degree of difficulty of assembly operations [44]. In accordance with Ben-Arieh (1994), assembly operations can be associated with parameters related to the geometry of the parts (geometry-based parameters) and the type of contact between the components (non-geometry-based parameters), see Table 1.

Table 1 - Parameters related to assembly operations (according to Ben-Arieh [44]).

\begin{tabular}{ll}
\hline \multicolumn{1}{c}{ Geometry-based parameters } & \multicolumn{2}{c}{ Non-geometrical parameters } \\
\hline (A) Shape & (N) Position contact \\
(B) Force required & (O) Snap contact \\
(C) Mating direction & (P) Spring contact \\
(D) Alignment of components & (Q) Gear contact \\
(E) Mating component's length & (R) Clamp fit \\
(F) Length of components intersection & (S) Belt contact \\
(G) Ratio of length to width (diameter) of the & \\
(H) Rating component & \\
& \\
(I) to the mated one & \\
(L) Amount of support required for the & \\
assembly operation & \\
(M) Interference (reachability) to the & \\
& assembled component
\end{tabular}

A number $l$ of parameters should be selected as criteria to evaluate the design-based complexity, according to the characteristics of the products to be assembled. Next, for deriving an integrated 
index, the weights $w_{q}$ of the $l$ parameters are assigned using the Analytic Hierarchy Process (AHP) approach [44-46], as follows:

$$
w_{q}=\left(\prod_{r=1}^{l} a_{q r}\right)^{1 / l} / \sum_{q=1}^{l}\left(\prod_{r=1}^{l} a_{q r}\right)^{1 / l} \quad(q=1, \ldots, l)
$$

where:

- $w_{q}$ is the weight of parameter $q$;

- $a_{q r}$ is the relative importance of parameter $q$ over parameter $r(r=1, \ldots, l)$;

- $l$ is the number of parameters.

Then, an evaluation of the degree of difficulty of each parameter in each workstation is obtained by a number $e$ of experts. More specifically, the degree of difficulty $D_{k q i}$ is the evaluation of the parameter $q$ in the workstation $i$ estimated by the expert $k$. The values $D_{k q i}$ are scores between 0 and 10. Depending on the weight $w_{q}$ of the $l$ parameters (Eq. (2)) and the degrees of difficulty $D_{k q i}$, the design-based complexity factors can be defined as [20]:

$$
C f_{D, i}=\sum_{q=1}^{l}\left(w_{q} \cdot \frac{1}{e} \cdot \sum_{k=1}^{e} D_{k q i}\right) \quad(i=1, \ldots, m)
$$

The relationship between Defects Per Unit $(D P U)$ and the two complexity factors, i.e., $C f_{P}$ and $C f_{D}$, was proved to follow a power-law behavior, see Eq. (4), by previous research in the electromechanical field [22, 27, 29]:

$$
D P U_{i}=a \cdot\left(C f_{P, i}\right)^{b} \cdot\left(C f_{D, i}\right)^{c}
$$

where $a, b$ and $c$ are nonlinear regression coefficients.

\section{A NOVEL DEFECT PREDICTION MODEL BASED ON STRUCTURAL COMPLEXITY}

The novel defect prediction model developed in this study is similar from an architectural point of view to the Shibata-Su model described in Section 2.3, but totally differs in the evaluation of product complexity. In the novel model, complexity is evaluated from an objective perspective using the structural complexity paradigm proposed in the studies of Sinha et al. [38] and Alkan [4], i.e., the Sinha-de Weck-Alkan model.

In this model, the Huckel's molecular orbital theory [47] is applied to the engineering domain to analyze the complexity of cyber-physical systems. According to Sinha et al. [38], any engineering system can be represented by several components that are connected in different ways. Each component can be thought of as an atom and the interfaces between them as inter-atomic interactions, i.e. chemical bonds [35]. Through this analogy, product complexity can be associated with the system's inherent structure and, therefore, with individual system entities and the effects of the system connectivity pattern [48]. This approach was successfully validated using pressure recording devices 
[35] and printing systems [28] as case studies. Accordingly, in the present paper, the authors decided to apply the approach in the electromechanical manufacturing field, slightly amended it to reflect the division of the process into workstations.

Assembly complexity $C_{i}$ related to each $i$-th workstation can be defined as [4, 28]:

$$
C_{i}=C_{1, i}+C_{2, i} \cdot C_{3, i}
$$

In Eq. (5), $C_{1, i}$ represents the sum of complexities of individual product parts in each $i$-th workstation and is calculated as follows:

$$
C_{1, i}=\sum_{p=1}^{N_{i}} \gamma_{p i}
$$

where, for each $i$-th workstation $(i=1, \ldots, m), N_{i}$ is the total number of product parts and $\gamma_{p i}$ is the handling complexity of part $p$. Each complexity $\gamma_{p i}$ may be intended as the ergonomic difficulty to interact with the part and can be measured according to the structural characteristics that cause difficulties during its handling [4]. As suggested by Alkan [4], handling complexity $\gamma_{p i}$ can be estimated as a function of the standard handling time of the part $p$, that involves the localization of the relevant box, moving arm to pick position, picking the relevant part and returning arm to work position.

$C_{2, i}$ is the complexity of liaisons related to the $i$-th workstation and is the sum of the complexities of pair-wise connections that exist in the product structure assembled in the workstation, as follows:

$$
C_{2, i}=\sum_{p=1}^{N_{i}-1} \sum_{r=p+1}^{N_{i}} \varphi_{p r i} \cdot A_{p r i}
$$

where, for each $i$-th workstation $(i=1, \ldots, m), \varphi_{\text {pri }}$ is the complexity in achieving a liaison between parts $p$ and $r$ and can be expressed by the relationships between the linked components and the nature of the connection, and $A_{\text {pri }}$ defines the binary adjacency matrix representing the connectivity structure of the system, as indicated in Eq. (8):

$$
A_{\text {pri }}= \begin{cases}1 & \text { if there is a connection between } p \text { and } r \text { in the } i \text {-th workstation } \\ 0 & \text { otherwise }\end{cases}
$$

The interface complexity $\varphi_{\text {pri }}$ may be estimated based on the standard completion time of the liaison between parts $p$ and $r$ in isolated conditions. In addition to the handling the connections, the completion time includes locating the connection areas, orienting and positioning the parts and the connector, placing the connectors and joining the parts, adjusting the connections, and a final check [4].

Finally, $C_{3, i}$ is the topological complexity of the $i$-th workstation and represents the complexity related to the architectural pattern of the assembled product. According to Sinha [28], it can be obtained from 
the matrix energy (also called graph energy) $E_{A i}$ of the adjacency matrix related to the $i$-th workstation [49], as shown in Eq. (9). $E_{A i}$ is designated by the sum of singular values $\delta_{p i}$ of the adjacency matrix of the product assembled in the $i$-th workstation

$$
C_{3, i}=\frac{E_{A i}}{N_{i}}=\frac{\sum_{p=1}^{N_{i}} \delta_{p i}}{N_{i}}
$$

where $N_{i}$ is the total number of singular values of the product connectivity matrix related to $i$-th workstation (i.e., the number of parts - or nodes - in the $i$-th workstation). It is recalled that, given an adjacency matrix $\boldsymbol{A}$, which is symmetric of size $N_{i}$ with the diagonal elements being all zeros, the singular values correspond to the absolute eigenvalues of the adjacency matrix $[28,50]$.

As observed by Sinha [28], matrix energy regime for graphs with a given number of nodes can be divided into (i) hyperenergetic, and (ii) hypoenergetic. An intermediate or transition regime between these two also exists [50]. The hyperenergetic regime is defined by graph energy greater than or equal to that of a fully connected graph, and the hypoenergetic regime is defined as shown in Eq. (10):

$$
E_{A i}= \begin{cases}\geq 2\left(N_{i}-1\right) & \text { hyperenergetic } \\ <N_{i} & \text { hypoenergetic }\end{cases}
$$

Hence, in terms of topological complexity metric, the regimes are defined as:

$$
C_{3, i}= \begin{cases}\geq 2\left(1-\frac{1}{N_{i}}\right) \approx 2 & \text { hyperenergetic } \\ <1 & \text { hypoenergetic }\end{cases}
$$

Note that for hyperenergetic regimes, $C_{3, i}$ can be approximated to 2 when $N_{i}$ is sufficiently large [50]. Translating the graph structures to system architectural pattern, typical topological complexity metric $C_{3, i}$ values can be associated to those forms, again when $N_{i}$ is sufficiently large: (i) $C_{3, i}<1$ for a centralized architecture, (ii) $1 \leq C_{3, i}<2$ for a hierarchical/layered architecture, and (iii) $C_{3, i} \geq 2$ for a distributed architecture [28]. Accordingly, $C_{3, i}$ increases as the system topology shifts from centralized architectures to more distributed architectures, as shown in Fig. 1 [4, 38]. 


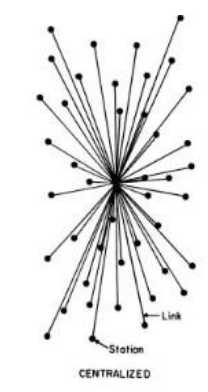

Centralized architecture

$C_{3, i}<1$

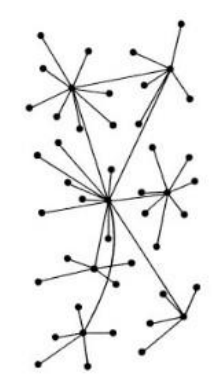

Hierarchical architecture

$1 \leq C_{3, i}<2$

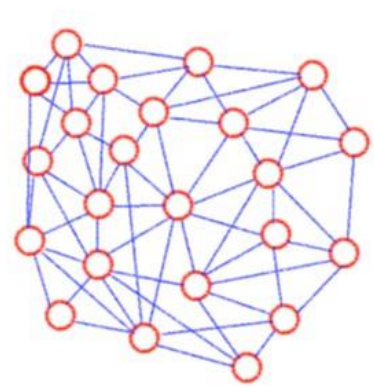

Distributed architecture

$C_{3, i} \geq 2$

Increasing Topological Complexity $C_{3, i}$

Figure 1 - Spectrum of architectural patterns based on topological complexity metric with their respective reference values (adapted from [28]).

Therefore, $C_{3, i}$ represents the intricateness of structural dependency among assembly and requires knowledge of the complete architecture of the system and, in this sense, contrary to the previous terms $C_{1, i}$ and $C_{2, i}$, denotes a global effect whose influence could be perceived during the system integration phase (Sinha, 2014). Therefore, the term $C_{2, i} \cdot C_{3, i}$ in Eq. (5) can be referred to as a general indicator of the system integration effort that allows distinguishing product architectures with similar parts and connections complexities.

To clarify how the complexity $C_{i}$ can be obtained, a pedagogical example is proposed. Let us consider an assembly process made up by a single workstation in which a simple product composed of 4 parts is assembled, as represented in Fig. 2. For simplicity, suppose that the 4 parts, as well as the connections between the parts, are identical. The standard handling time of each $p$-th part is $\gamma_{p}=5 \mathrm{~s}$ (with $p=1, \ldots, 4$ ), while the standard completion time of the connection between parts $p$ and $r$ is $\varphi_{p r}=30 \mathrm{~s}$ (with $p=1, \ldots, 3$ and $r=p+1, \ldots, 4$ ). According to Eq. (6), the handling complexity is $C_{1}=\sum_{p=1}^{4} \gamma_{p}=20 \mathrm{~s}=0.33 \mathrm{~min}$. The complexity of connections is, by implementing Eq. (7), $C_{2}=$ $\sum_{p=1}^{3} \sum_{r=p+1}^{4} \varphi_{p r} \cdot A_{p r}=90 \mathrm{~s}=1.5 \mathrm{~min}$, as 3 connections between the parts exist.

The graph energy of the associated adjacency matrix $\boldsymbol{A}$, represented in Fig. 2, is computed as the sum of its singular values, that are the absolute values of the eigenvalues of the matrix $\boldsymbol{A}$. In detail, the eigenvalues of the matrix $\boldsymbol{A}$ are $-1.73,1.73$ and 0 with multiplicity 2 . Thus, $E_{A}=2 \cdot 1.73=3.46$. According to Eq. (9), it is obtained that $C_{3}=\frac{3.46}{4}=0.87$. Since $C_{3}<1$, the product topology can be qualified as a centralized architecture. Finally, by applying Eq. (5), the structural complexity is $C=$ $C_{1}+C_{2} \cdot C_{3}=1.64 \mathrm{~min}$. 


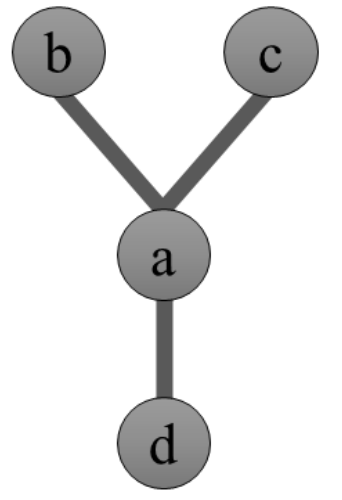

$$
\begin{gathered}
\text { Adjacency matrix } \\
\boldsymbol{A}=\left(\begin{array}{llll}
0 & 1 & 1 & 1 \\
1 & 0 & 0 & 0 \\
1 & 0 & 0 & 0 \\
1 & 0 & 0 & 0
\end{array}\right) \\
\text { b } \\
\text { c }
\end{gathered}
$$

Figure 2 - Connectivity structure of a simple product composed of four parts and its associated adjacency matrix $\boldsymbol{A}$.

In the proposed model, the structural complexity defined in Eq. (5) is used as predictor for the DPU occurring in each $i$-th workstation $\left(D P U_{i}\right)$. To construct the prediction model, a preliminary set of historical data is necessary. To this aim, an adequate quantity of production units in each workstation should be examined (indicatively, at least fifteen to twenty units for each workstation). This amount of data is reasonably acceptable for the statistical data analysis [51]. Clearly, increasing the number of units collected will increase the accuracy of the statistical analysis, but it will also increase the associated costs.

As it will be described in the next Section 4, the relationship between the structural complexity $C_{i}$, defined in Eq. (5), and $D P U_{i}$ was studied by using empirical data belonging to a low-volume production of wrapping machines. The model that best interpolates experimental data is the following:

$$
D P U_{i}=c \cdot\left(C_{i}\right)^{d}
$$

where $c$ and $d$ are nonlinear regression coefficients.

These results are in line with the preliminary findings obtained by Alkan [4] and Sinha [28], where the complexity was found to be in a super-linear relationship with real assembly time, evaluated also considering possible errors and reworks.

The structure of the proposed defect prediction model reflects that of Shibata-Su model (see Eq. 4). Both models use complexity factors as predictors. The Shibata-Su model highlights two complexity contributions: (i) the process-based complexity by the $C f_{P, i}$ factor and (ii) the design-based complexity by the $C f_{D, i}$ factor. On the other side, the structural complexity factor, $C_{i}$ (see Eq.5), incorporates in a single element both the complexity of the process and the design. However, there is a deep conceptual difference between the two approaches. In the Shibata-Su model, while $C f_{P, i}$ is estimated 
by objective process data (i.e. standard times), $C f_{D, i}$ is obtained from a subjective inspector evaluation. In the proposed model, instead, $C_{i}$ is based only on an objective estimation of the structural product characteristics. The first method uses a mix of objective and subjective information; the second one uses only objective information to describe product complexity. Therefore, despite the similarity of the predictors, the two models are profoundly different from an operational point of view.

Moreover, it should be noted that decoupling the complexity into two distinct factors can be considered as an artificial operation. In practical applications, there is no clear distinction between the complexity due to the process and the complexity due to the design, as these are often related. To make this concept clearer, just think of the times for handling components or connecting parts. These are not only process-related but are also closely associated with the design characteristics of the parts to be assembled and the nature of their connections. Therefore, since process and design coexist together, the novel model seems to be more suitable to evaluate the complexity of a product as a whole. The structural complexity factor $C_{i}$ considers the complexity of individual components, connections and product topology, without directly making a distinction between process and design.

As a result, the proposed approach, depending solely on physical design information, can be considered more useful than the Shibata-Su model, especially in the early design stages when real production data or the physical mockup are not available.

As above mentioned, in the following section, the proposed model is applied to a case study of wrapping machines assembly and compared with the Shibata-Su model described in Section 2.3.

\section{CASE STUDY}

\subsection{ASSEMBLY PROCESS OF WRAPPING MACHINES}

In the proposed case study, wrapping machines, and specifically the rotating ring wrapping machines, are analyzed [52]. Such machines are electromechanical devices adopted at the end of production lines to pack palletized loads with a stretch plastic film by using a rotating ring. This study considers the rotating ring wrapping machines produced by the Italian company Tosa Group S.p.A. (see Fig. 3). The process to manufacture these wrapping machines can be classified as a low-volume production because, in a typical year, about 50 highly tailored units are assembled.

Three central units compose the rotating wrapping machines: (i) mechanical, (ii) electrical and electronic and (iii) software. A fixed and a moving part are distinguished in the mechanical unit, as shown in Fig. 3. In detail, the fixed part consists of (i) a frame, (ii) a cutting-hooking-welding unit, and (iii) a pantograph presser. The frame is a load-bearing structure, dimensioned to guarantee strength and durability, composed of boxes and profiles in high-strength sheet steel. The cutting- 
hooking-welding unit automatically cuts the plastic film by a heated metal wire and heat-seals the last tail to the load with a specific plate. Finally, the pantograph presser stabilizes the palletized load, exerting pressure on its top during the wrapping process.

On the other hand, two devices are assembled in the moving part, namely a rotating ring and a prestretching device. The rotating ring is made of a calendered steel profile, which is light but very strong and suitable for high speeds. It is moved by a belt connected to an electric motor. The rotation of the ring around the palletized load is combined, during the wrapping cycle, with vertical sliding. The prestretching device is attached to the rotating ring and enables the machine to perform the following three functions: (i) the pulling/unwinding, (ii) the pre-stretching and positioning of the plastic film, (iii) the wrapping of the pallet with the required number of wraps.

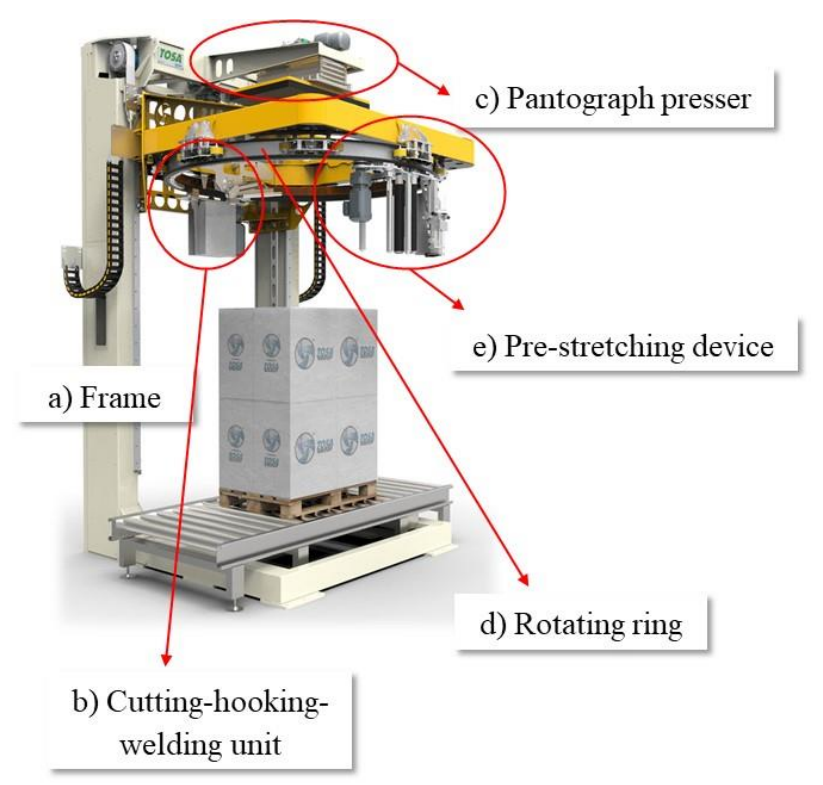

Figure 3 - Mechanical group and principal components of a rotating ring wrapping machine produced by the Italian company Tosa Group S.p.A.

The wiring of the components, sensors and onboard motors and the general electric panel are included in the electrical and electronic unit. The software unit, whose programming is handled by a specialized external supplier, aims at controlling the machine and communicating with the operator. A typical work cycle of a wrapping machine is described below. The palletized load is transported by a roller or belt conveyor system into the area bounded by the carriage. Next, the pantograph presser descends by pressing down on top of the palletized load to ensure stability during the film wrapping phase. The carriage descends, the ring begins to rotate and, simultaneously, the plastic film moves through the pretensioner and is distributed around the load. After a number of wrappings that depends on the palletised load, the wrapping cycle ends, the cutting-hooking-welding unit removes the tail of 
the plastic film and the load is left free to be transported to the next production station. Finally, a new pallet enters the ring perimeter of the machine and the cycle repeats.

Because of the complex nature and the high number of wrapping machine components, this article focuses on only one device, i.e., the pre-stretching device. The primary reason is that although each machine differs from the others in some details, this device is common to all rotating ring wrapping machines. The proposed approach, however, can be extended and implemented to the whole wrapping machine.

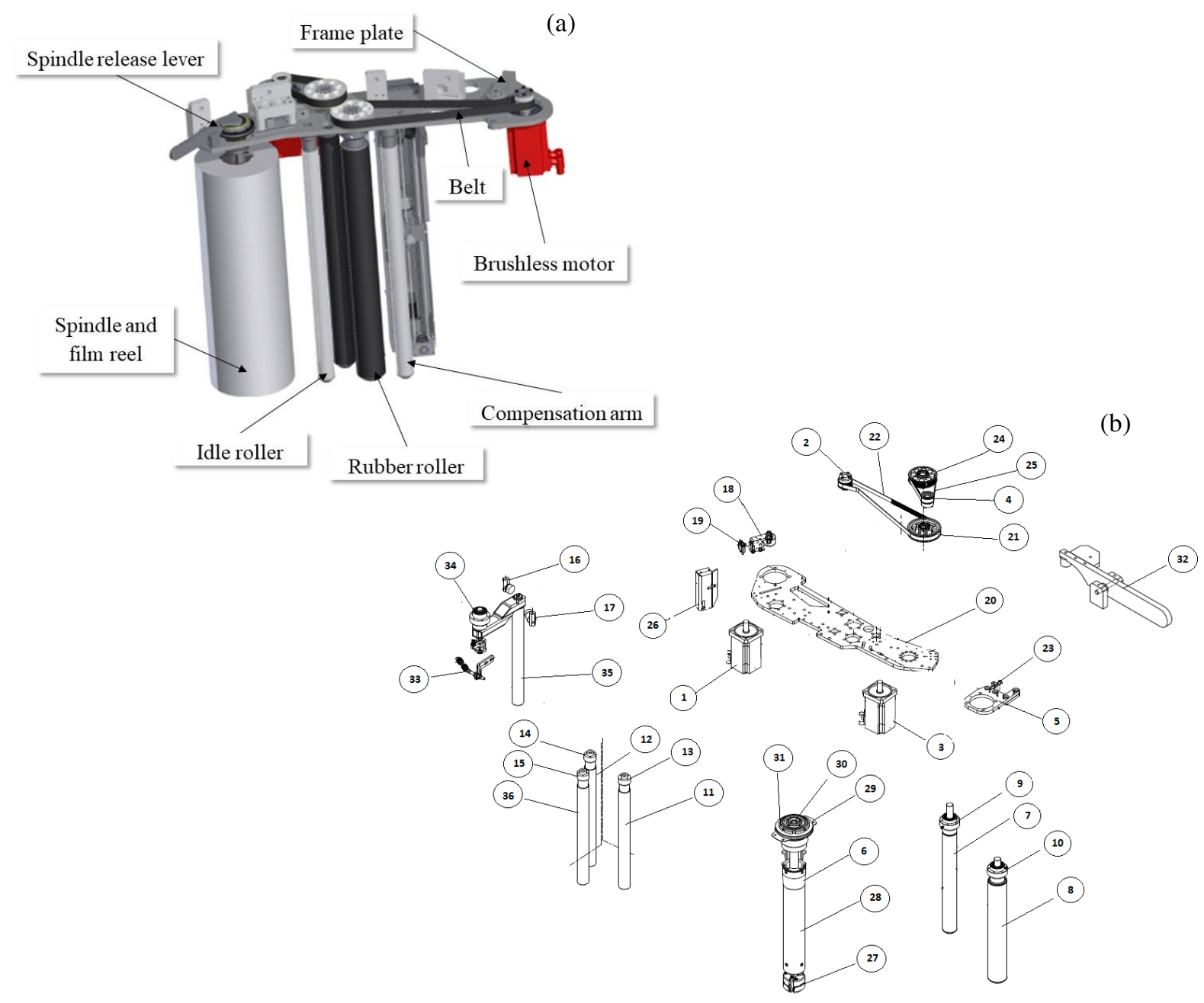

Figure 4 - (a) 3D CAD model with main components, and (b) exploded view of the pre-stretching device.

As illustrated in Fig. 4, the pre-stretching device is installed on a support structure called "frame plate". The stretch film moves through two rubber rollers, each connected by a belt transmission system to a brushless motor: the speeds of the two rollers are therefore independent of each other. When coming into contact with the surface of the two rollers, the film stretches proportionally to the difference in speed, thus significantly increasing the film's length. The electronic system measures the speed through dedicated sensors and keeps the film tension constant during its application over 
the entire surface of the pallet. In addition, the pre-stretching device can be equipped with a patented mandrel that replaces the empty film reel automatically.

The breakdown of the pre-stretching device assembly process into 29 workstations is shown in Table 2. These workstations are assembly steps defined within operation standards, i.e. instruction sheets for work procedure $[20,22]$. The first nine workstations are assembled on the bench, while the remaining ones are assembled on the frame plate. Table 2 also reports the experimental $D P U$ values occurring under stable process conditions in each workstation, obtained by drawing on the company's historical data collected over the past five years. Such values can thus be considered an indication of the average defect rate of the assembly process under optimal working conditions. 
Table 2 - Subdivision of the assembly process of the pre-stretching device into workstations (WS) with the related experimental $D P U$.

\begin{tabular}{|c|c|c|c|}
\hline $\begin{array}{l}\text { WS } \\
\text { no. }\end{array}$ & Ref. Fig. 4b & WS description & $\begin{array}{c}\text { Experimental } \\
\operatorname{DPU}_{i}\end{array}$ \\
\hline 1 & 1,2 & Motor no. 1 bench assembly & 0.0364 \\
\hline 2 & 3,4 & Motor no. 2 bench assembly & 0.0364 \\
\hline 3 & 5 & Support plate of motor no. 2 bench assembly & 0.0182 \\
\hline 4 & 6 & Spindle bench assembly & 0.0000 \\
\hline 5 & $7,8,9,10,11,12,36$ & Rubber tyres bench assembly & 0.1091 \\
\hline 6 & $13,14,15$ & Idle rolls bench assembly & 0.0545 \\
\hline 7 & 16,17 & Rubberized pads bench assembly & 0.0000 \\
\hline 8 & 18,19 & Belt tensioner device bench assembly & 0.0364 \\
\hline 9 & & $\begin{array}{l}\text { Driven wheels of transmission system bench } \\
\text { assembly }\end{array}$ & 0.0000 \\
\hline 10 & 20 & Pre-stretch frame plate preparation & 0.0182 \\
\hline 11 & & $\begin{array}{l}\text { Rubber rollers on pre-stretch frame plate } \\
\text { assembly }\end{array}$ & 0.0182 \\
\hline 12 & & Idle rollers on pre-stretch frame plate assembly & 0.0182 \\
\hline 13 & & Motor no. 1 on frame plate assembly & 0.0000 \\
\hline 14 & 21,22 & Transmission system of motor no. 1 assembly & 0.0000 \\
\hline 15 & 23 & Motor no. 2 on frame plate assembly & 0.0182 \\
\hline 16 & 24,25 & Transmission system of motor no. 2 assembly & 0.0364 \\
\hline 17 & 26 & $\begin{array}{l}\text { Motor no. } 1 \text { bracket on pre-stretch frame plate } \\
\text { assembly }\end{array}$ & 0.0000 \\
\hline 18 & & $\begin{array}{l}\text { Belt tensioner on pre-stretch frame plate } \\
\text { assembly }\end{array}$ & 0.0364 \\
\hline 19 & & Transmission system of motor no. 1 calibration & 0.0364 \\
\hline 20 & & Transmission system of motor no. 2 calibration & 0.0364 \\
\hline 21 & 27,28 & $\begin{array}{l}\text { Spindle preparation for assembly on pre-stretch } \\
\text { frame plate }\end{array}$ & 0.0000 \\
\hline 22 & $29,30,31$ & $\begin{array}{l}\text { Spindle group on pre-stretch frame plate } \\
\text { assembly }\end{array}$ & 0.0364 \\
\hline 23 & & $\begin{array}{l}\text { Rubber pads on pre-stretch frame plate } \\
\text { assembly }\end{array}$ & 0.0000 \\
\hline 24 & & Motor assembly no. 1 final steps & 0.0545 \\
\hline 25 & & Motor assembly no. 2 final steps & 0.0545 \\
\hline 26 & 32 & Spindle release lever bench assembly & 0.0000 \\
\hline 27 & & $\begin{array}{l}\text { Spindle release lever on pre-stretch frame plate } \\
\text { assembly }\end{array}$ & 0.0000 \\
\hline 28 & 33,34 & Compensation arm bench assembly & 0.0909 \\
\hline 29 & 35 & $\begin{array}{l}\text { Compensation arm on pre-stretch frame plate } \\
\text { assembly }\end{array}$ & 0.0000 \\
\hline
\end{tabular}




\subsection{THE NOVEL DEFECT PREDICTION MODEL: DPU VS STRUCTURAL COMPLEXITY}

The novel prediction model that uses the structural complexity paradigm as a predictor is empirically derived in this section.

Table 3 reports, for each $i$-th workstation, the complexities $C_{1, i}, C_{2, i}$ and $C_{3, i}$, evaluated according to Eqs. (6), (7), and (9), respectively, and the final assembly complexity $C_{i}$ derived by Eq. (5). Specifically, $C_{1, i}$ is estimated considering the standard handling time of the parts that are assembled in the corresponding workstation, and $C_{2, i}$ the standard completion time of the connection between the parts. Finally, $C_{3, i}$ is obtained from the graph energy of the adjacency matrix related to the $i$-th workstation and the number of parts assembled $N_{i}$. For instance, in workstation no. 14, only two parts are assembled: the driven wheel and the drive belt. As shown in Table 3, the standard handling time of the two parts is $0.14 \mathrm{~min}$ and the time for connecting them is $0.44 \mathrm{~min}$. For these two parts, the adjacency matrix is $\boldsymbol{A}=\left(\begin{array}{ll}0 & 1 \\ 1 & 0\end{array}\right)$ and its graph energy $E_{A}$ is 2 (the eigenvalues of the matrix $\boldsymbol{A}$ are 1 and -1). Thus, the resulting complexity $C_{3}$ is 1 . Consequently, by applying Eq. (5), product complexity of this workstation is $0.58 \mathrm{~min}$.

To relate $D P U_{i}$ versus $C_{i}$, different models were tested and compared (see Table 4 ). The adequacy of the models was assessed through the analysis of regression residuals and the $S$ value as a measure of goodness-of-fit. A power curve fitting (model no. 3 in Table 4) was the best model to define such a relationship. Accordingly, the final model developed for wrapping machines assembly is the following:

$$
D P U_{i}=3.05 \cdot 10^{-3} \cdot\left(C_{i}\right)^{1.58}
$$

Fig. 5 plots the new defect prediction model defined in Eq. (13) and the residual plots. The normal probability plot indicates that the residuals do not show significant deviations from the normal distribution. The normality of residuals is also not rejected by performing the Anderson-Darling test at a significance level of 5\% [53]. The plot of residuals versus order exhibits a horizontal band around the line of residuals (value 0 ) and neither systematic effects in the data due to time or collection order are shown. To evaluate the goodness of fit of a nonlinear regression model, the $S$ value (standard error of the regression - also called standard error of the estimate) should be used instead of $R^{2}[54,55]$. For the model provided in Eq. (13), the $S$ value is equal to 0.018 , indicating that the experimental values of $D P U$ fall an average absolute distance of 0.018 units from the $D P U$ values predicted by the model. 
Table 3 - Variables and predictions related to the novel defect prediction model: $D P U$ vs $C$.

\begin{tabular}{|c|c|c|c|c|c|c|}
\hline WS no. & $N_{i}$ & $C_{1, i}[\mathrm{~min}]$ & $C_{2, i}[\mathrm{~min}]$ & $C_{3, i}$ & $C_{i}[\mathrm{~min}]$ & Predicted $D P U_{i}$ \\
\hline 1 & 14 & 2.19 & 5.11 & 0.60 & 5.27 & 0.0424 \\
\hline 2 & 14 & 2.28 & 5.33 & 0.59 & 5.41 & 0.0443 \\
\hline 3 & 10 & 1.19 & 4.77 & 0.80 & 5.01 & 0.0391 \\
\hline 4 & 3 & 0.78 & 3.14 & 0.25 & 1.57 & 0.0062 \\
\hline 5 & 14 & 1.24 & 11.13 & 0.47 & 6.47 & 0.0587 \\
\hline 6 & 12 & 1.63 & 6.53 & 0.62 & 5.68 & 0.0478 \\
\hline 7 & 4 & 0.73 & 2.91 & 0.25 & 1.46 & 0.0055 \\
\hline 8 & 8 & 0.25 & 2.22 & 1.90 & 4.47 & 0.0327 \\
\hline 9 & 4 & 0.08 & 0.33 & 0.25 & 0.16 & 0.0002 \\
\hline 10 & 11 & 0.99 & 3.97 & 0.75 & 3.97 & 0.0271 \\
\hline 11 & 26 & 1.07 & 4.27 & 0.88 & 4.83 & 0.0369 \\
\hline 12 & 39 & 1.19 & 4.77 & 0.83 & 5.15 & 0.0409 \\
\hline 13 & 5 & 0.74 & 2.96 & 0.25 & 1.48 & 0.0057 \\
\hline 14 & 2 & 0.14 & 0.44 & 1.00 & 0.58 & 0.0013 \\
\hline 15 & 16 & 1.73 & 6.90 & 0.48 & 5.01 & 0.0391 \\
\hline 16 & 2 & 0.09 & 0.80 & 3.14 & 2.60 & 0.0139 \\
\hline 17 & 3 & 0.20 & 0.78 & 0.25 & 0.39 & 0.0007 \\
\hline 18 & 5 & 0.18 & 1.64 & 1.97 & 3.41 & 0.0213 \\
\hline 19 & 12 & 1.74 & 4.05 & 0.69 & 4.55 & 0.0336 \\
\hline 20 & 12 & 1.90 & 4.43 & 0.66 & 4.81 & 0.0366 \\
\hline 21 & 15 & 0.45 & 1.79 & 0.25 & 0.90 & 0.0026 \\
\hline 22 & 34 & 1.36 & 12.23 & 0.44 & 6.730 & 0.0625 \\
\hline 23 & 5 & 0.47 & 1.89 & 0.25 & 0.94 & 0.0028 \\
\hline 24 & 3 & 0.12 & 1.04 & 2.88 & 3.09 & 0.0182 \\
\hline 25 & 3 & 0.12 & 1.08 & 2.77 & 3.11 & 0.0184 \\
\hline 26 & 6 & 0.24 & 0.95 & 0.25 & 0.48 & 0.0009 \\
\hline 27 & 6 & 0.80 & 7.20 & 0.25 & 2.60 & 0.0139 \\
\hline 28 & 20 & 1.26 & 11.32 & 0.60 & 8.05 & 0.0830 \\
\hline 29 & 4 & 0.56 & 5.00 & 0.25 & 1.81 & 0.0078 \\
\hline
\end{tabular}

Table 4 - Comparison of different models defining the relationship between defects per unit and assembly complexity.

\begin{tabular}{|c|c|c|c|}
\hline No. & & Model & $\begin{array}{c}S \\
\text { (Standard } \\
\text { error of the } \\
\text { regression) }\end{array}$ \\
\hline (1) & Linear model with intercept & $D P U_{i}=9.82 \cdot 10^{-3} \cdot C_{i}-8.16 \cdot 10^{-3}$ & 0.01859 \\
\hline (2) & Power model with intercept & $D P U_{i}=9.91 \cdot 10^{-3} \cdot C_{i}^{1.61}+3.50 \cdot 10^{-4}$ & 0.01861 \\
\hline (3) & Power model & $D P U_{i}=3.05 \cdot 10^{-3} \cdot C_{i}^{1.58}$ & 0.01826 \\
\hline (4) & Exponential model & $D P U_{i}=6.45 \cdot 10^{-3} \cdot e^{0.34 \cdot C_{i}}$ & 0.01848 \\
\hline
\end{tabular}



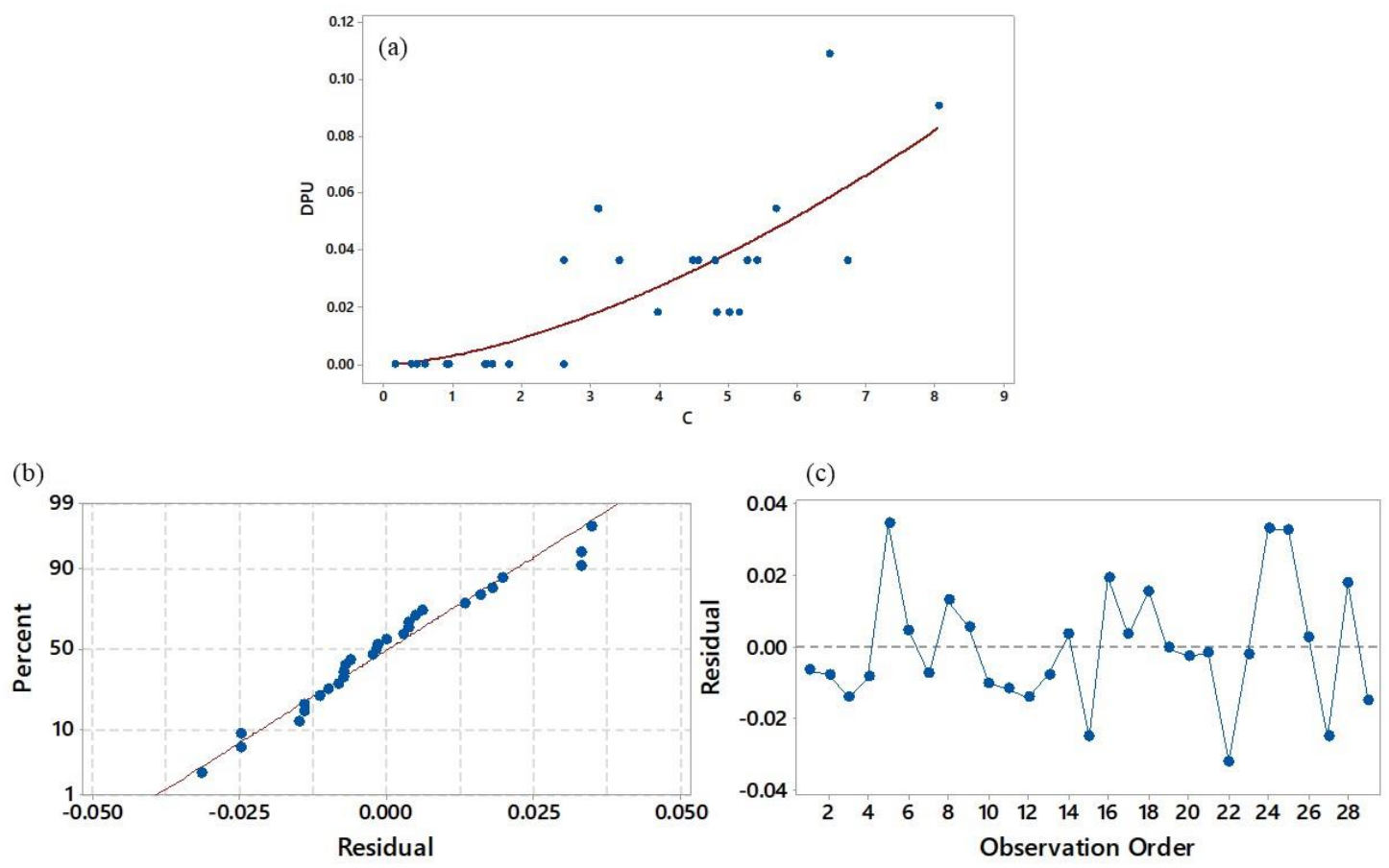

Figure 5 - (a) $D P U$ vs $C$ : defect prediction model and experimental data; Residual plots: (b) Normal Probability Plot and (c) Residuals vs Order.

\subsection{SHIBATA-SU MODEL: $D P U$ VS PROCESS AND DESIGN BASED COMPLEXITY}

This section presents the implementation of the Shibata-Su model, described in Section 2.3, in order to compare the obtained predictions with those obtained by using the new model shown in Eq. (13).

Regarding the first predictor, $C f_{P, i}$, see Eq. (1), each workstation was subdivided into a certain number of elementary operations, $N_{a, i}$, ranging from 1 to 12 (see Table 5). Concerning assembly times, instead of using Sony Standard Time (typical of Sony's home audio products), the time of each job element was evaluated by considering the average value of 3 measurements of the assembly standard time spent by the operator in the job element. The threshold assembly time $t_{0}$ was set at 0.04 min, which corresponds to the time required to perform the least complex job element. The assembly time $T A T_{i}$ is shown in Table 5, as well as the final value of the first predictor, $C f_{P, i}$, calculated according to Eq. (1), separately for each $i$-th workstation. 
Table 1 - Variables and predictions related to the Shibata-Su model: $D P U$ vs $C f_{P}$ and $C f_{D}$.

\begin{tabular}{cccccc}
\hline WS no. & $\boldsymbol{N}_{\boldsymbol{a}, \boldsymbol{i}}$ & $\boldsymbol{T A}_{\boldsymbol{i}}[\mathbf{m i n}]$ & $\boldsymbol{C}_{\boldsymbol{P}_{\boldsymbol{P} \boldsymbol{i}}[\mathbf{m i n}]}$ & $\boldsymbol{C}_{\boldsymbol{D}, \boldsymbol{i}}$ & ${\text { Predicted } \boldsymbol{D} \boldsymbol{P} \boldsymbol{U}_{\boldsymbol{i}}^{(*)}}$ \\
\hline 1 & 6 & 7.30 & 7.1 & 4.38 & 0.0214 \\
2 & 6 & 7.61 & 7.4 & 4.56 & 0.0250 \\
3 & 3 & 5.96 & 5.8 & 5.06 & 0.0287 \\
4 & 3 & 3.92 & 3.8 & 4.31 & 0.0126 \\
5 & 12 & 12.37 & 11.9 & 5.69 & 0.0715 \\
6 & 12 & 8.16 & 7.7 & 4.89 & 0.0320 \\
7 & 3 & 3.64 & 3.5 & 2.76 & 0.0030 \\
8 & 3 & 2.47 & 2.4 & 3.48 & 0.0045 \\
9 & 2 & 0.41 & 0.3 & 3.68 & 0.0012 \\
10 & 3 & 4.96 & 4.8 & 4.21 & 0.0142 \\
11 & 4 & 5.34 & 5.2 & 5.35 & 0.0312 \\
12 & 6 & 5.96 & 5.7 & 5.14 & 0.0298 \\
13 & 1 & 3.70 & 3.7 & 5.09 & 0.0205 \\
14 & 2 & 0.97 & 0.9 & 5.40 & 0.0084 \\
15 & 4 & 8.63 & 8.5 & 4.94 & 0.0355 \\
16 & 2 & 0.89 & 0.8 & 4.94 & 0.0060 \\
17 & 1 & 0.98 & 0.9 & 4.22 & 0.0041 \\
18 & 2 & 1.82 & 1.7 & 4.27 & 0.0067 \\
19 & 2 & 5.79 & 5.7 & 5.19 & 0.0306 \\
20 & 2 & 6.33 & 6.3 & 5.21 & 0.0332 \\
21 & 2 & 2.24 & 2.2 & 5.20 & 0.0147 \\
22 & 6 & 13.59 & 13.4 & 5.59 & 0.0738 \\
23 & 2 & 2.36 & 2.3 & 4.13 & 0.0075 \\
24 & 1 & 1.15 & 1.1 & 4.07 & 0.0041 \\
25 & 1 & 1.20 & 1.2 & 4.25 & 0.0049 \\
26 & 1 & 1.19 & 1.2 & 4.06 & 0.0042 \\
27 & 3 & 8.00 & 7.9 & 4.72 & 0.0293 \\
28 & 9 & 12.58 & 12.2 & 5.54 & 0.0672 \\
29 & 3 & 5.56 & 5.4 & 4.96 & 0.0257 \\
\hline & 3 & & & &
\end{tabular}

As far as the methodology to evaluate the second predictor, $C f_{D}$, is concerned, it is the one developed by $\mathrm{Su}$ et al. [20] for electromechanical products as the wrapping machine is substantially an electromechanical equipment. In this case, regarding Eqs. (2) and (3), 11 design parameters were selected by adapting Ben Arieh's approach to the case of wrapping machines, see Table 5. A pair of engineers and four assembly operators were requested to compare the relative importance of each parameter in determining the difficulty to assemble a part into a product. The scores used to assess the relative importance between each pair of parameters varied from a minimum of 1 , representing equal importance between the two parameters, to a maximum of 9, indicating the dominant importance of the considered parameter over the other [20]. The output of this step is a pairwise comparison matrix for each evaluator, for a total of six matrices. Then, by the geometric mean, as suggested by Dong and Saaty [56], the individual ratings were aggregated into a single pairwise 
comparison matrix representative of group judgment (see Table A.1). The weights $w_{q}$ of the $l$ parameters are finally derived from this matrix by implementing Eq. (2), and are listed in Table 6.

Table 6 - Parameters selected from those in Table 1 for evaluating the design-based complexity factor and their weights.

\begin{tabular}{cclc}
\hline $\begin{array}{c}\text { Design } \\
\text { parameter }\end{array}$ & $\begin{array}{c}\text { Ref. } \\
\text { Table 1 }\end{array}$ & Design parameter description & $\begin{array}{c}\text { Weight } \\
\boldsymbol{w}_{\boldsymbol{q}}\end{array}$ \\
\hline P1 & (A) & Shape of mating objects & 0.139 \\
P2 & (B) & Force required & 0.120 \\
P3 & (D) & Alignment of components & 0.150 \\
P4 & (C) & Mating direction & 0.169 \\
P5 & (H) & Ratio of the mating component's weight to the mated one & 0.094 \\
P6 & (G) & Ratio of length to width (diameter) of the mating component & 0.091 \\
P7 & (M) & Reachability to the assembled component & 0.056 \\
P8 & (E) & Mating component's length & 0.064 \\
P9 & (L) & Amount of support required for the assembly & 0.037 \\
P10 & (I) & Stability of the resultant assembly & 0.041 \\
P11 & (F) & Length of components intersection & 0.038 \\
\hline
\end{tabular}

Besides, the $e=6$ experts were asked to evaluate the degree of difficulty of each design parameter in each workstation. More in detail, the question asked to the experts was the following [52]: "How much does the q-th parameter affect the assembly difficulty in the $i$-th workstation on a scale from 0 to 10, where 0 corresponds to no difficulty and 10 corresponds to maximum difficulty?". To cope with the alignment of the assessment scales, the framework provided in Table A.2 was explained to each expert. This tool entailed the adoption of a standard scale of judgements by defining conventional degrees of difficulty.

Six matrices were obtained, one for each expert. Then, by averaging the evaluations of the six experts, for each $q$-th parameter in each $i$-th workstation, the matrix of the degrees of difficulty was derived (see Table A.3).

The design-based complexity factor of each workstation, $C f_{D, i}$, is finally obtained by applying Eq. (3) and by combining the weights of the parameters and the degrees of difficulty matrix reported respectively in Table 6 and Table A.3. The obtained values are listed in Table 5.

Experimental $D P U$ were analyzed using the power-law regression model shown in Eq. (4) by using the software $M A T L A B^{\circledR}$. The defect prediction model obtained, which will be marked henceforth with an asterisk (*) to distinguish it from the novel model reported in Eq. (13), is the following [52] (see also Fig. 6): 


$$
D P U_{i}^{*}=5.04 \cdot 10^{-5} \cdot\left(C f_{P, i}\right)^{0.77} \cdot\left(C f_{D, i}\right)^{3.08}
$$

The DPU predicted by using Eq. (14) are listed in Table 5. The analysis of the residuals plots shows that the model describes well the trend of the $D P U$ as a function of the two assembly complexity factors. The normal probability plot shows a slight hypernormality, indicating a higher concentration of residuals around the central value. However, by performing the Anderson-Darling test, the normality of residuals cannot be rejected at a significance level of 5\%. Furthermore, no systematic effects are evidenced by the plot of residuals versus order. The $S$ value is 0.024 , representing that the experimental values of $D P U$ fall a standard distance of 0.024 units from the $D P U$ values predicted by Eq. (14).
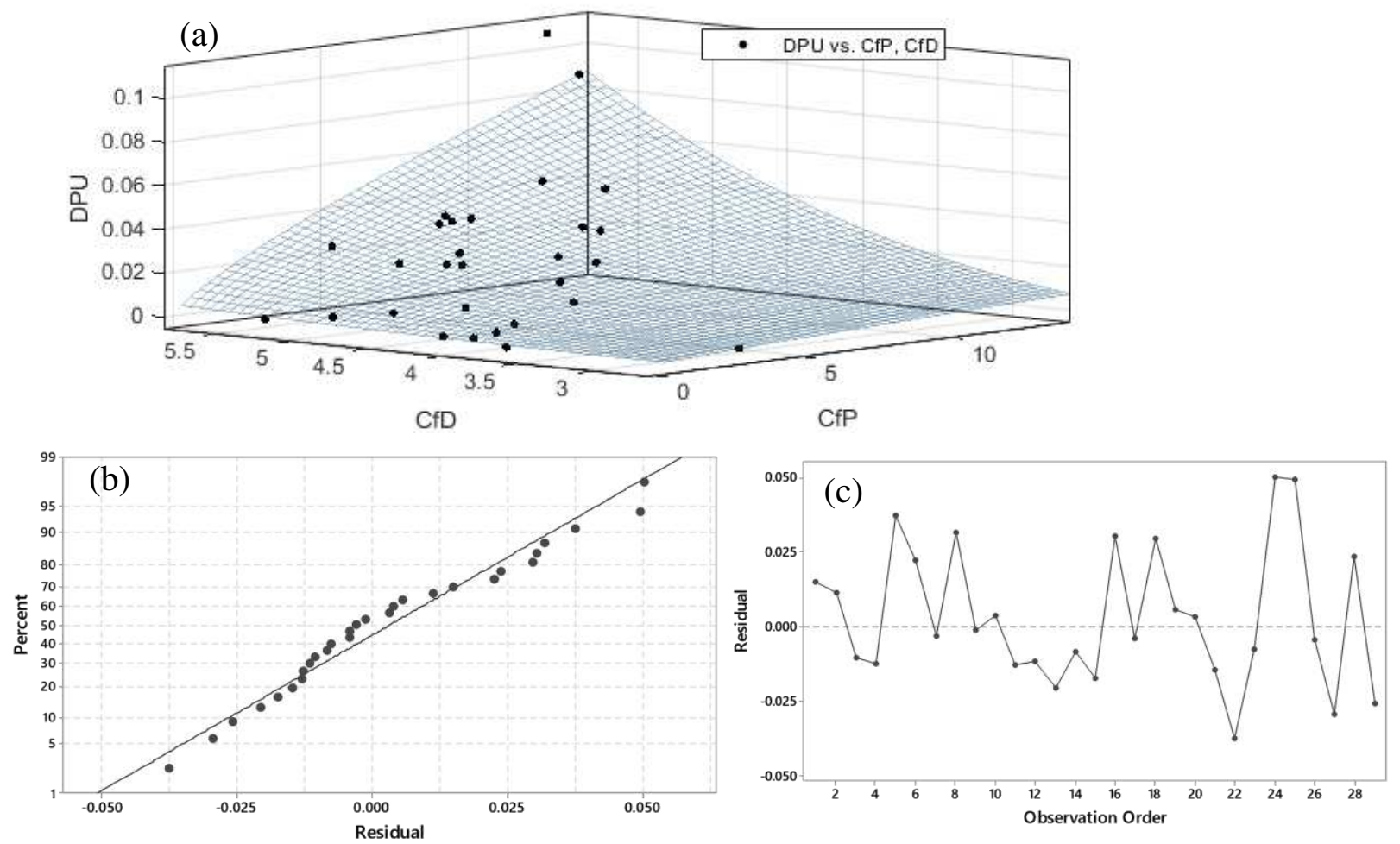

Figure 6 - (a) $D P U$ vs $C f_{P}$ and $C f_{D}$ : defect prediction model and experimental data; Residual plots:

(b) Normal Probability Plot and (c) Residuals vs Order.

\subsection{COMPARISON BETWEEN THE TWO MODELS}

Fig. 7 illustrates the $95 \%$ prediction interval obtained for the $D P U$ estimated using defect prediction models shown in Eq. (13) and (14), separately for each workstation. In detail, the upper and lower prediction limits, the predicted values and the experimental values are reported. The complete list of the prediction ranges and their width is provided in Table A.4. These prediction intervals, obtained by $M I N I T A B^{\circledR}$, represent the ranges in which the predicted responses for single new observations are expected to fall. It should be noted that negative values of the lower limits of prediction intervals of 
$D P U$ are set equal to zero. Accordingly, for most workstations, the prediction interval is not symmetric with respect to the predicted $D P U_{i}$.

According to results provided in Fig. 7 and Table A.4 and by comparing Fig. 5 and 6, it is observed that the model proposed in this study allows obtaining more accurate estimates of $D P U$ because the average absolute distance between experimental values and the regression model is 0.018 , while for the other model is 0.024 . Furthermore, $D P U$ values estimated by implementing the novel model are also generally more precise since the related uncertainty in the estimate is tendentially lower (see the limits and the width of the prediction intervals in Fig. 7 and Table A.4). 

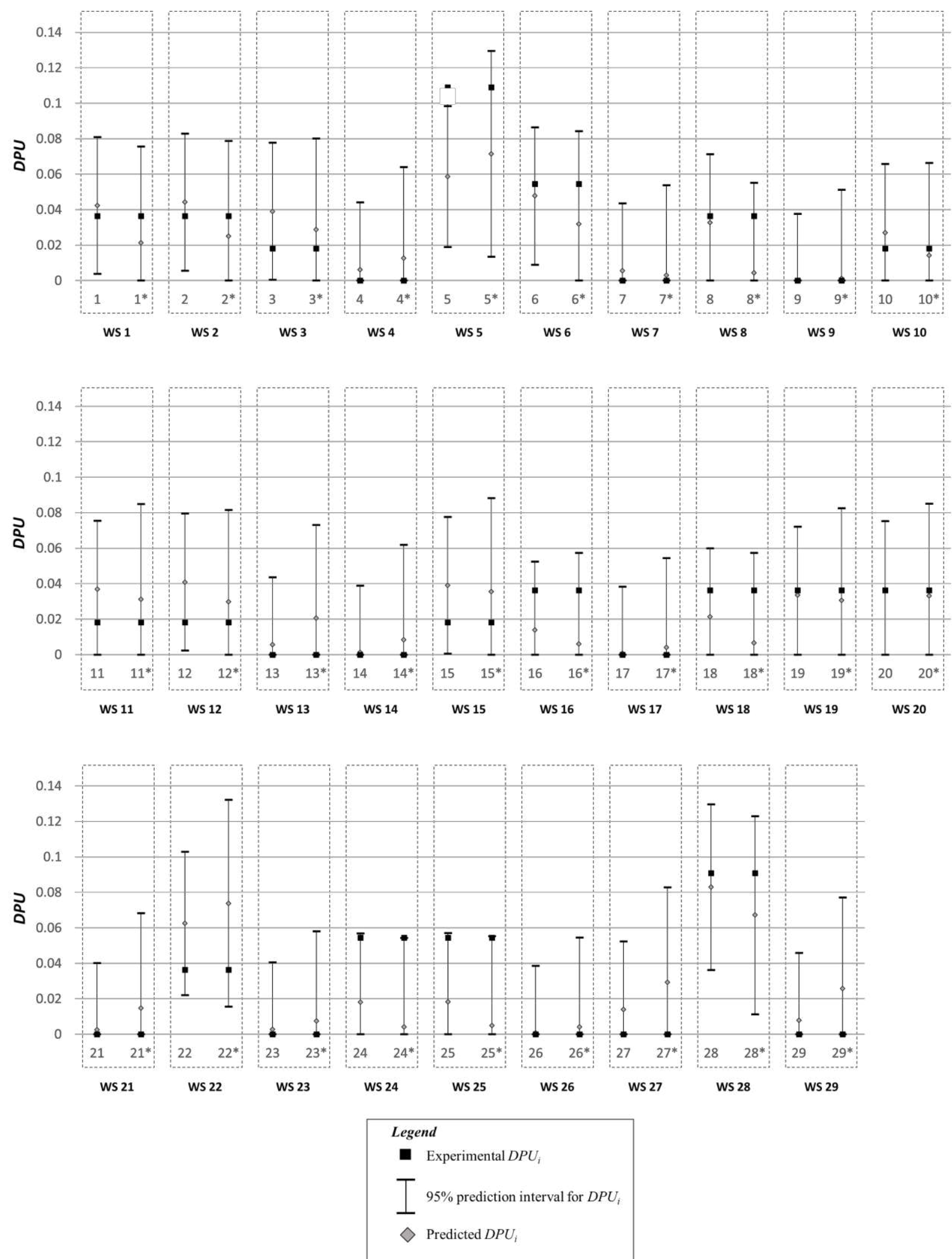

Figure 7 - Graphical comparison of $95 \%$ prediction interval for $D P U_{i}$ obtained using the novel defect prediction model and the Shibata-Su model. Values referring to the Shibata-Su model are asterisked. 


\section{CONCLUSIONS}

Although defect prediction is of utmost importance from the earliest stages of product design and related quality inspection design, most approaches are not directly applicable because they rely on operators' prior subjective knowledge and are designed for specific industrial applications. Addressing this problem, the present paper proposes a new approach to predict product defects from a more objective complexity assessment. This is one of the first attempts to predict product defects and improve product quality with a purely objective assessment of the complexity of the assembled product, without the need for operator evaluations and assembly expertise. The defect prediction model proposed, that is suitable for manufacturing assembly, is based on the relationship between defect rates and the structural complexity paradigm developed by Sinha [28] and Alkan [4]. The predictor of such a model is the structural product complexity which is formulated by considering both complexities of product elements and effects of product assembly topology. This novel prediction model is compared with one of the most accredited models in the literature, i.e., the Shibata-Su model. In the novel model, product complexity is approached based on objective product characteristics, while in the Shibata-Su model the complexity is evaluated through a mix of objective and subjective data. Besides, the objective perspective of the novel approach seems to be preferable as it considers in a combined factor both the process complexity and the design complexity, without separating the two aspects. As a result, the novel model, depending solely on physical design information, can be considered more usable than the Shibata-Su model, especially in the early design stages when real production data or the physical mockup are not available. The assembly of wrapping machines was used as a case study for developing and testing the novel prediction model. This process belongs to the category of low-volume productions (production rate: 50 machines assembled each year). In this situation, identifying an appropriate defect prediction model is essential since traditional statistical methods are generally not suitable or not applicable. The comparison between the novel model and the Shibata-Su model pointed out that, despite the architectural similarities, the former allows for more accurate and precise estimates of $D P U$. The novel model, providing reliable and accurate defectiveness previsions, can act both as a tool for quantitatively estimating defects of newly developed products and as a decision support tool for the assembly quality-oriented design and optimization. Indeed, engineers can employ this prediction model to get a quantitative estimation of $D P U$ and accordingly design or re-design the process trying to minimize the defectiveness rates, by reducing assembly complexity.

The main limitation of the applicability of this method in real applications concerns the construction of the probabilistic model, which requires a preliminary estimate of the DPU in each workstation. In the case of assembly of electromechanical products, the model developed for wrapping machines can 
be considered a suitable equation to model DPU. However, the two regression coefficients may vary according to the specific industrial application. As a first approximation, it is acceptable to apply the proposed model to obtain a preliminary prediction of DPU and, when real experimental data are collected, update the model to refine the regression parameter estimates and improve the accuracy of the predictions.

Future research will be aimed at exploiting this novel defect prediction to support the design of quality-inspection strategies in low-volume manufacturing and evaluate its effect on the inspection planning process.

\section{ACKNOWLEDGEMENTS}

The authors gratefully acknowledge the company Tosa Group S.p.A. (Italy) for the collaboration in this project.

\section{DECLARATION}

\section{Ethical Approval}

The authors respect the Ethical Guidelines of the Journal.

\section{Consent to Participate}

Not applicable

\section{Consent to Publish}

Not applicable

\section{Authors Contributions}

The authors have provided an equal contribution to the drafting of the paper.

\section{Funding}

This work has been partially supported by the "Italian Ministry of Education, University and Research", Award "TESUN-83486178370409 finanziamento dipartimenti di eccellenza CAP. 1694 TIT. 232 ART. 6".

\section{Competing Interests}

The authors do not have conflict of interest

\section{Availability of data and materials}

Not applicable 


\section{REFERENCES}

1. Bednar S, Rauch E (2019) Modeling and application of configuration complexity scale: concept for customized production. Int J Adv Manuf Technol 100:485-501

2. Shoval S, Efatmaneshnik M (2019) Managing complexity of assembly with modularity: a cost and benefit analysis. Int J Adv Manuf Technol 105:3815-3828

3. Bedny GZ, Karwowski W, Bedny IS (2012) Complexity evaluation of computer-based tasks. Int J Hum Comput Interact 28:236-257

4. Alkan B (2019) An experimental investigation on the relationship between perceived assembly complexity and product design complexity. Int J Interact Des Manuf 13:1145-1157

5. Falck A-C, Örtengren R, Rosenqvist M, Söderberg R (2017) Basic complexity criteria and their impact on manual assembly quality in actual production. Int J Ind Ergon 58:117-128

6. Krugh M, Antani K, Mears L, Schulte J (2016) Prediction of Defect Propensity for the Manual Assembly of Automotive Electrical Connectors. Procedia Manuf 5:144-157

7. Hasan SM, Baqai AA, Butt SU, quz Zaman UK (2018) Product family formation based on complexity for assembly systems. Int J Adv Manuf Technol 95:569-585

8. Boothroyd G, Alting L (1992) Design for assembly and disassembly. CIRP Ann 41:625-636

9. Miyakawa S (1986) The Hitachi Assemblability Evaluation Method (AEM). In: Proceedings of 1st Int. Conf. on Product Design for Assembly, 1986

10. Zhu X, Hu SJ, Koren Y, et al (2007) Sequence planning to minimize complexity in mixedmodel assembly lines. In: 2007 IEEE International Symposium on Assembly and Manufacturing. IEEE, pp 251-258

11. Hinckley CM (1994) A global conformance quality model. A new strategic tool for minimizing defects caused by variation, error, and complexity. PhD dissertation, Mechanical Engineering Department, Stanford University

12. Shibata H, Cheldelin B, Ishii K (2003) Assembly quality methodology: A new method for evaluating assembly complexity in globally distributed manufacturing. In: ASME 2003 International Mechanical Engineering Congress and Exposition. The American Society of Mechanical Engineers, November 15-21, 2003 Washington, DC, USA, pp 335-344

13. ElMaraghy WH, Urbanic RJ (2004) Assessment of manufacturing operational complexity. CIRP Ann 53:401-406

14. Zaeh MF, Wiesbeck M, Stork S, Schubö A (2009) A multi-dimensional measure for determining the complexity of manual assembly operations. Prod Eng 3:489

15. Samy SN, ElMaraghy H (2010) A model for measuring products assembly complexity. Int J Comput Integr Manuf 23:1015-1027 
16. Alkan B, Vera D, Chinnathai MK, Harrison R (2017) Assessing complexity of componentbased control architectures used in modular automation systems. Int J Comput Electr Eng 9:393-402

17. Mattsson S (2013) What is perceived as complex in final assembly? $\mathrm{PhD}$ dissertation, Department of Product and Production Development, Chalmers University of Technology

18. Falck A-C, Tarrar M, Mattsson S, et al (2017) Assessment of manual assembly complexity: a theoretical and empirical comparison of two methods. Int J Prod Res 55:7237-7250

19. Falck A-C, Örtengren R, Rosenqvist M (2012) Relationship between complexity in manual assembly work, ergonomics and assembly quality. In: Ergonomics for Sustainability and Growth, NES 2012 (Nordiska Ergonomisällskapet) konferens, Saltsjöbaden, Stockholm, 1922 augusti, 2012

20. Su Q, Liu L, Whitney DE (2010) A systematic study of the prediction model for operatorinduced assembly defects based on assembly complexity factors. IEEE Trans Syst Man Cybern - Part A Syst Humans 40:107-120

21. Falck A-C, Örtengren R, Rosenqvist M, Söderberg R (2016) Criteria for assessment of basic manual assembly complexity. Procedia CIRP 44:424-428

22. Shibata H (2002) Global assembly quality methodology: a new methodology for evaluating assembly complexities in globally distributed manufacturing. $\mathrm{PhD}$ dissertation, Mechanical Engineering Department, Stanford University

23. Antani KR (2014) A Study of the Effects of Manufacturing Complexity on Product Quality in Mixed-Model Automotive Assembly. PhD dissertation, Mechanical Engineering Department, Clemson University

24. Falck A-C, Örtengren R, Rosenqvist M, Söderberg R (2017) Proactive assessment of basic complexity in manual assembly: development of a tool to predict and control operator-induced quality errors. Int J Prod Res 55:4248-4260

25. Galetto M, Verna E, Genta G (2020) Accurate estimation of prediction models for operatorinduced defects in assembly manufacturing processes. Qual Eng 32:595-613

26. Le Y, Qiang S, Liangfa S (2012) A novel method of analyzing quality defects due to human errors in engine assembly line. In: Information Management, Innovation Management and Industrial Engineering (ICIII), 2012 International Conference on Information Management, Innovation Management and Industrial Engineering (ICIII). IEEE, 20-21 October 2012, Sanya, China, pp 154-157

27. Verna E, Genta G, Galetto M, Franceschini F (2021) Defect prediction models to improve assembly processes in low-volume productions. Procedia CIRP 97:148-153

28. Sinha K (2014) Structural complexity and its implications for design of cyber-physical 
systems. PhD dissertation, Engineering Systems Division, Massachusetts Institute of Technology

29. Galetto M, Verna E, Genta G, Franceschini F (2020) Uncertainty evaluation in the prediction of defects and costs for quality inspection planning in low-volume productions. Int $\mathbf{J}$ Adv Manuf Technol 108:3793-3805

30. Verna E, Genta G, Galetto M, Franceschini F (2021) Towards Zero Defect Manufacturing: probabilistic model for quality control effectiveness. In: 2021 IEEE International Workshop on Metrology for Industry 4.0 \& IoT (MetroInd4.0\&IoT). IEEE, 7-9 June 2021, Rome, Italy, pp 522-526. doi: 10.1109/MetroInd4.0IoT51437.2021.948

31. Verna E, Genta G, Galetto M, Franceschini F (2021) Inspection planning by defect prediction models and inspection strategy maps. Prod Eng 1-19. https://doi.org/10.1007\%2Fs11740-02101067-x

32. Verna E, Genta G, Galetto M, Franceschini F (2020) Planning offline inspection strategies in low-volume manufacturing processes. Qual Eng 32:705-720

33. Koons GF, Luner JJ (1991) SPC in low-volume manufacturing: a case study. J Qual Technol 23:287-295

34. Galetto M, Genta G, Maculotti G, Verna E (2020) Defect Probability Estimation for HardnessOptimised Parts by Selective Laser Melting. Int J Precis Eng Manuf 21:1739-1753

35. Alkan B, Vera D, Ahmad B, Harrison R (2017) A method to assess assembly complexity of industrial products in early design phase. IEEE Access 6:989-999

36. Richardson M, Jones G, Torrance M, Baguley T (2006) Identifying the task variables that predict object assembly difficulty. Hum Factors 48:511-525

37. Lee T-S (2003) Complexity theory in axiomatic design. PhD dissertation, Department of Mechanical Engineering, Massachusetts Institute of Technology

38. Sinha K, de Weck OL, Onishi M, et al (2012) Structural complexity metric for engineered complex systems and its application. In: Gain Competitive Advantage by Managing Complexity: Proceedings of the 14th International DSM Conference Kyoto, Japan. pp 181194

39. Krugh M, Antani K, Mears L, Schulte J (2016) Statistical modeling of defect propensity in manual assembly as applied to automotive electrical connectors. Procedia CIRP 44:441-446

40. Franceschini F, Galetto M, Genta G, Maisano DA (2018) Selection of quality-inspection procedures for short-run productions. Int J Adv Manuf Technol 99:2537-2547

41. Genta G, Galetto M, Franceschini F (2018) Product complexity and design of inspection strategies for assembly manufacturing processes. Int J Prod Res 56:4056-4066

42. Aft LS (2000) Work Measurement and Methods Improvement. John Wiley \& Sons, Hoboken, 


\section{NJ, USA}

43. Yamagiwa Y (1988) An assembly ease evaluation method for product designers: DAC. Techno Japan 21:26-29

44. Ben-Arieh D (1994) A methodology for analysis of assembly operations' difficulty. Int J Prod Res 32:1879-1895

45. Wei CC, Chien CF, Wang MJJ (2005) An AHP-based approach to ERP system selection. Int J Prod Econ 96:47-62

46. Saaty TL (1980) The Analytic Hierarchy Process. McGraw-Hill, New York

47. Hückel E (1932) Quantentheoretische Beiträge zum Problem der aromatischen und ungesättigten Verbindungen. III. Zeitschrift für Phys 76:628-648

48. Alkan B, Harrison R (2019) A virtual engineering based approach to verify structural complexity of component-based automation systems in early design phase. J Manuf Syst $53: 18-31$

49. Nikiforov V (2007) The energy of graphs and matrices. J Math Anal Appl 326:1472-1475

50. Li X, Shi Y, Gutman I (2012) Hyperenergetic and Equienergetic Graphs. In: Graph Energy. Springer, New York, NY, pp 193-201

51. Montgomery DC (2019) Introduction to statistical quality control, 8th ed. Wiley Global Education

52. Verna E, Genta G, Galetto M, Franceschini F (2020) Defect prediction model for wrapping machines assembly. In: Proceedings of the 4th International Conference on Quality Engineering and Management. 21-22 september, University of Minho, Braga, Portugal, pp 115-134. ISSN: 21843481, ISBN: 978-989549110-0

53. Devore JL (2011) Probability and Statistics for Engineering and the Sciences. Cengage learning, Boston, USA

54. Bates DM, Watts DG (1988) Nonlinear Regression Analysis and Its Applications. John Wiley \& Sons, Inc., Hoboken, NJ, USA

55. Spiess AN, Neumeyer N (2010) An evaluation of R2 as an inadequate measure for nonlinear models in pharmacological and biochemical research: A Monte Carlo approach. BMC Pharmacol 10:1-11 


\section{APPENDICES}

Table A.1 - Paired comparison matrix of design parameters for evaluating the design-based assembly complexity in the Shibata-Su model.

\begin{tabular}{c|ccccccccccc||c}
\hline $\begin{array}{c}\text { Design } \\
\text { parameter }\end{array}$ & P1 & P2 & P3 & P4 & P5 & P6 & P7 & P8 & P9 & P10 & P11 & $\left(\prod_{r=1}^{l} a_{q r}\right)^{\frac{1}{l}}$ \\
\hline P1 & 1.00 & 1.32 & 1.96 & 0.78 & 0.60 & 2.59 & 5.58 & 2.72 & 2.93 & 1.53 & 2.38 & 1.761 \\
P2 & 0.76 & 1.00 & 3.05 & 0.83 & 1.26 & 0.79 & 1.67 & 3.63 & 2.51 & 1.27 & 2.89 & 1.529 \\
P3 & 0.51 & 0.33 & 1.00 & 1.26 & 3.04 & 1.26 & 3.80 & 2.12 & 5.10 & 4.93 & 7.41 & 1.907 \\
P4 & 1.29 & 1.21 & 0.79 & 1.00 & 2.74 & 4.39 & 3.53 & 1.36 & 3.37 & 5.13 & 3.69 & 2.151 \\
P5 & 1.66 & 0.79 & 0.33 & 0.53 & 1.00 & 1.47 & 1.02 & 1.10 & 3.45 & 5.44 & 0.97 & 1.192 \\
P6 & 0.39 & 1.26 & 0.79 & 0.23 & 0.68 & 1.00 & 3.52 & 1.41 & 5.38 & 2.67 & 1.21 & 1.161 \\
P7 & 0.18 & 0.60 & 0.26 & 0.28 & 0.98 & 0.28 & 1.00 & 1.28 & 1.76 & 1.31 & 3.69 & 0.714 \\
P8 & 0.37 & 0.28 & 0.47 & 0.73 & 0.91 & 0.71 & 0.78 & 1.00 & 2.00 & 1.51 & 1.85 & 0.810 \\
P9 & 0.34 & 0.40 & 0.20 & 0.30 & 0.29 & 0.19 & 0.57 & 0.50 & 1.00 & 1.51 & 1.24 & 0.466 \\
P10 & 0.66 & 0.79 & 0.20 & 0.20 & 0.18 & 0.37 & 0.76 & 0.66 & 0.66 & 1.00 & 1.69 & 0.523 \\
P11 & 0.42 & 0.35 & 0.13 & 0.27 & 1.03 & 0.82 & 0.27 & 0.54 & 0.81 & 0.59 & 1.00 & 0.480 \\
\hline \hline
\end{tabular}


Table A.2 - List of parameters used to evaluate the design-based y complexity in the Shibata-Su model, with examples of the degrees of difficulty to be assigned during the assessment.

\begin{tabular}{|c|c|c|c|c|}
\hline Parameter & $\begin{array}{l}\text { Parameter } \\
\text { description }\end{array}$ & $\begin{array}{l}\text { Degree of difficulty } \\
0-3\end{array}$ & $\begin{array}{l}\text { Degree of } \\
\text { difficulty } \\
3-6\end{array}$ & $\begin{array}{c}\text { Degree of difficulty } \\
6-10\end{array}$ \\
\hline P1 & $\begin{array}{c}\text { Shape of mating } \\
\text { objects }\end{array}$ & 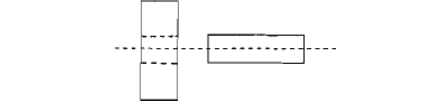 & $\ldots \ldots$ & $\ldots$ \\
\hline $\mathrm{P} 2$ & Force required & $\begin{array}{l}\text { Simple coupling (no manual } \\
\text { tool required) }\end{array}$ & $\begin{array}{l}\text { Forced coupling } \\
\text { (manual tool } \\
\text { required) }\end{array}$ & $\begin{array}{l}\text { Coupling with } \\
\text { hydraulic press } \\
(20000 \mathrm{~kg})\end{array}$ \\
\hline P3 & $\begin{array}{l}\text { Alignment of } \\
\text { components }\end{array}$ & Mechanical stop & $\begin{array}{l}\text { Stop with } \\
\text { reference }\end{array}$ & No reference stop \\
\hline P4 & Mating direction & $\begin{array}{l}\text { Axial } \\
\square+\infty \\
\square-\square\end{array}$ & Eccentric axial & Eccentric radial \\
\hline P5 & $\begin{array}{l}\text { Ratio of the mating } \\
\text { component's weight to } \\
\text { the mated one }\end{array}$ & $\begin{array}{l}\text { Bearing lift } \\
\text { (approx. } 1 \mathrm{~kg} \text { ) }\end{array}$ & $\begin{array}{l}\text { Idle roller lift } \\
\text { (approx. } 4 \mathrm{~kg} \text { ) }\end{array}$ & $\begin{array}{l}\text { Frame plate lift } \\
\text { (approx. } 7 \mathrm{~kg} \text { ) }\end{array}$ \\
\hline P6 & $\begin{array}{l}\text { Ratio of length to } \\
\text { width (diameter) of } \\
\text { the mating component }\end{array}$ & Belt tensioner device & Frame plate & Roller \\
\hline P7 & $\begin{array}{l}\text { Reachability to the } \\
\text { assembled component }\end{array}$ & $\begin{array}{l}\text { Simple coupling } \\
\qquad \sqrt{6}-(\theta)-\end{array}$ & $\begin{array}{l}\text { Medium } \\
\text { complexity } \\
\text { coupling }\end{array}$ & Complex coupling \\
\hline P8 & $\begin{array}{l}\text { Mating component's } \\
\text { length }\end{array}$ & Flanged sleeve & Brushless motor & Roller \\
\hline P9 & $\begin{array}{l}\text { Amount of support } \\
\text { required for the } \\
\text { assembly }\end{array}$ & No support & $\begin{array}{c}\text { Medium stable } \\
\text { support }\end{array}$ & Very stable support \\
\hline P10 & $\begin{array}{l}\text { Stability of the } \\
\text { resultant assembly }\end{array}$ & Very stable resultant assembly & $\begin{array}{l}\text { Medium stable } \\
\text { resultant } \\
\text { assembly }\end{array}$ & $\begin{array}{l}\text { Poorly stable } \\
\text { resulting assembly }\end{array}$ \\
\hline P11 & $\begin{array}{l}\text { Length of components } \\
\text { intersection }\end{array}$ & $\begin{array}{l}\text { Low component coupling } \\
\text { length }\end{array}$ & $\begin{array}{c}\text { Medium } \\
\text { component } \\
\text { coupling length }\end{array}$ & $\begin{array}{l}\text { High component } \\
\text { coupling length }\end{array}$ \\
\hline
\end{tabular}


Table A.3 - Degrees of difficulty matrix for evaluating the design-based complexity in the ShibataSu model.

\begin{tabular}{|c|c|c|c|c|c|c|c|c|c|c|c|}
\hline \multirow[b]{2}{*}{ Workstation } & \multicolumn{11}{|c|}{ Design parameter } \\
\hline & $\mathrm{P} 1$ & $\mathrm{P} 2$ & P3 & $\mathrm{P} 4$ & P5 & P6 & P7 & P8 & P9 & $\mathrm{P} 10$ & P11 \\
\hline 1 & 4.00 & 4.17 & 4.17 & 4.50 & 5.17 & 3.67 & 4.33 & 3.17 & 6.00 & 5.83 & 5.50 \\
\hline 2 & 4.33 & 4.33 & 4.17 & 4.50 & 5.17 & 3.67 & 5.67 & 3.33 & 6.00 & 5.83 & 6.33 \\
\hline 3 & 5.83 & 6.50 & 5.50 & 4.33 & 4.00 & 3.50 & 5.00 & 4.00 & 6.50 & 5.00 & 6.00 \\
\hline 4 & 3.67 & 4.00 & 3.50 & 3.33 & 4.83 & 3.83 & 6.00 & 5.17 & 6.00 & 6.83 & 6.67 \\
\hline 5 & 4.17 & 7.33 & 4.83 & 5.33 & 4.67 & 6.33 & 5.83 & 6.67 & 7.83 & 6.50 & 7.33 \\
\hline 6 & 3.83 & 5.67 & 4.83 & 3.50 & 4.00 & 5.83 & 5.00 & 6.50 & 6.33 & 6.50 & 6.67 \\
\hline 7 & 2.83 & 3.50 & 3.00 & 2.67 & 1.50 & 2.00 & 2.67 & 1.67 & 3.00 & 4.00 & 4.83 \\
\hline 8 & 3.83 & 4.17 & 4.17 & 3.17 & 2.33 & 1.83 & 3.50 & 1.83 & 4.67 & 5.00 & 5.50 \\
\hline 9 & 5.00 & 2.83 & 6.00 & 2.83 & 2.33 & 2.67 & 2.83 & 2.33 & 1.17 & 6.17 & 5.17 \\
\hline 10 & 4.17 & 3.50 & 5.00 & 2.00 & 6.17 & 5.33 & 2.67 & 4.33 & 5.67 & 5.83 & 4.83 \\
\hline 11 & 4.00 & 4.67 & 6.17 & 3.67 & 6.33 & 7.17 & 4.50 & 7.67 & 5.33 & 6.83 & 5.67 \\
\hline 12 & 4.00 & 4.00 & 6.00 & 3.67 & 6.00 & 6.83 & 4.50 & 7.17 & 5.00 & 7.17 & 5.33 \\
\hline 13 & 3.83 & 5.17 & 6.67 & 4.83 & 5.83 & 4.83 & 3.50 & 5.00 & 5.50 & 5.33 & 5.00 \\
\hline 14 & 6.17 & 5.00 & 6.67 & 6.33 & 3.17 & 4.00 & 6.00 & 3.83 & 3.17 & 6.67 & 6.17 \\
\hline 15 & 4.17 & 5.00 & 6.50 & 4.50 & 5.17 & 5.00 & 4.17 & 4.83 & 5.17 & 5.00 & 3.67 \\
\hline 16 & 5.50 & 4.83 & 5.83 & 6.00 & 2.67 & 3.67 & 6.00 & 3.00 & 2.83 & 6.17 & 6.17 \\
\hline 17 & 3.17 & 3.67 & 6.33 & 5.00 & 4.00 & 3.33 & 3.33 & 3.17 & 3.17 & 4.83 & 4.00 \\
\hline 18 & 3.67 & 3.67 & 6.50 & 5.17 & 3.00 & 3.33 & 4.00 & 2.83 & 3.00 & 6.33 & 2.67 \\
\hline 19 & 4.33 & 5.17 & 7.33 & 5.67 & 3.50 & 5.00 & 5.83 & 3.00 & 3.83 & 6.83 & 4.67 \\
\hline 20 & 4.33 & 5.17 & 7.33 & 5.67 & 3.50 & 4.50 & 5.50 & 3.83 & 3.83 & 6.67 & 5.67 \\
\hline 21 & 3.50 & 4.17 & 6.17 & 4.83 & 6.33 & 7.00 & 4.50 & 7.17 & 4.33 & 4.50 & 4.67 \\
\hline 22 & 5.50 & 5.67 & 5.33 & 5.17 & 5.67 & 6.50 & 6.33 & 6.83 & 5.17 & 4.50 & 4.67 \\
\hline 23 & 3.50 & 4.67 & 4.67 & 4.00 & 3.50 & 3.17 & 4.33 & 3.67 & 3.67 & 5.83 & 6.17 \\
\hline 24 & 3.17 & 3.17 & 5.17 & 5.33 & 3.83 & 3.00 & 4.67 & 2.67 & 3.17 & 5.00 & 4.83 \\
\hline 25 & 3.33 & 3.33 & 5.67 & 5.50 & 3.83 & 3.17 & 4.50 & 3.17 & 3.00 & 5.00 & 4.83 \\
\hline 26 & 4.00 & 2.83 & 5.50 & 5.00 & 2.50 & 3.33 & 3.67 & 4.00 & 2.83 & 5.00 & 4.83 \\
\hline 27 & 4.33 & 4.67 & 5.83 & 5.00 & 4.17 & 3.50 & 4.50 & 4.83 & 3.33 & 6.00 & 5.17 \\
\hline 28 & 4.83 & 4.33 & 6.33 & 5.17 & 5.17 & 6.17 & 5.17 & 7.33 & 5.33 & 6.83 & 6.33 \\
\hline 29 & 3.83 & 4.50 & 5.83 & 5.83 & 3.33 & 5.00 & 4.67 & 6.00 & 3.00 & 5.83 & 6.83 \\
\hline
\end{tabular}


Table A.4 - Comparison of predictions obtained using the novel defect prediction model, see Eq. (13), and an alternative one existing in the literature (based on the Shibata-Su model), see Eq. (14).

\begin{tabular}{|c|c|c|c|c|}
\hline & \multicolumn{2}{|c|}{ 95\% prediction interval for $D P U_{i}$} & \multicolumn{2}{|c|}{$95 \%$ prediction interval for $D P U_{i}^{*}$} \\
\hline WS no. & Range & Width & Range & Width \\
\hline 1 & $(0.0038 ; 0.0810)$ & 0.0772 & $(0.0000 ; 0.0755)$ & 0.0755 \\
\hline 2 & $(0.0056 ; 0.0829)$ & 0.0773 & $(0.0000 ; 0.0788)$ & 0.0788 \\
\hline 3 & $(0.0005 ; 0.0777)$ & 0.0771 & $(0.0000 ; 0.0802)$ & 0.0802 \\
\hline 4 & $(0.0000 ; 0.0442)$ & 0.0442 & $(0.0000 ; 0.0639)$ & 0.0639 \\
\hline 5 & $(0.0189 ; 0.0985)$ & 0.0796 & $(0.0134 ; 0.1295)$ & 0.1161 \\
\hline 6 & $(0.0090 ; 0.0865)$ & 0.0775 & $(0.0000 ; 0.0843)$ & 0.0843 \\
\hline 7 & $(0.0000 ; 0.0435)$ & 0.0435 & $(0.0000 ; 0.0538)$ & 0.0538 \\
\hline 8 & $(0.0000 ; 0.0713)$ & 0.0713 & $(0.0000 ; 0.0551)$ & 0.0551 \\
\hline 9 & $(0.0000 ; 0.0376)$ & 0.0376 & $(0.0000 ; 0.0512)$ & 0.0512 \\
\hline 10 & $(0.0000 ; 0.0657)$ & 0.0657 & $(0.0000 ; 0.0663)$ & 0.0663 \\
\hline 11 & $(0.0000 ; 0.0755)$ & 0.0755 & $(0.0000 ; 0.0849)$ & 0.0849 \\
\hline 12 & $(0.0023 ; 0.0795)$ & 0.0772 & $(0.0000 ; 0.0815)$ & 0.0815 \\
\hline 13 & $(0.0000 ; 0.0436)$ & 0.0436 & $(0.0000 ; 0.0730)$ & 0.0730 \\
\hline 14 & $(0.0000 ; 0.0388)$ & 0.0388 & $(0.0000 ; 0.0618)$ & 0.0618 \\
\hline 15 & $(0.0006 ; 0.0777)$ & 0.0771 & $(0.0000 ; 0.0883)$ & 0.0883 \\
\hline 16 & $(0.0000 ; 0.0524)$ & 0.0524 & $(0.0000 ; 0.0573)$ & 0.0573 \\
\hline 17 & $(0.0000 ; 0.0382)$ & 0.0382 & $(0.0000 ; 0.0544)$ & 0.0544 \\
\hline 18 & $(0.0000 ; 0.0600)$ & 0.0600 & $(0.0000 ; 0.0573)$ & 0.0573 \\
\hline 19 & $(0.0000 ; 0.0722)$ & 0.0722 & $(0.0000 ; 0.0826)$ & 0.0826 \\
\hline 20 & $(0.0000 ; 0.0752)$ & 0.0752 & $(0.0000 ; 0.0850)$ & 0.0850 \\
\hline 21 & $(0.0000 ; 0.0402)$ & 0.0402 & $(0.0000 ; 0.0682)$ & 0.0682 \\
\hline 22 & $(0.0221 ; 0.1029)$ & 0.0808 & $(0.0155 ; 0.1322)$ & 0.1167 \\
\hline 23 & $(0.0000 ; 0.0405)$ & 0.0405 & $(0.0000 ; 0.0581)$ & 0.0581 \\
\hline 24 & $(0.0000 ; 0.0569)$ & 0.0569 & $(0.0000 ; 0.0544)$ & 0.0544 \\
\hline 25 & $(0.0000 ; 0.0571)$ & 0.0571 & $(0.0000 ; 0.0553)$ & 0.0553 \\
\hline 26 & $(0.0000 ; 0.0385)$ & 0.0385 & $(0.0000 ; 0.0545)$ & 0.0545 \\
\hline 27 & $(0.0000 ; 0.0524)$ & 0.0524 & $(0.0000 ; 0.0828)$ & 0.0828 \\
\hline 28 & $(0.0362 ; 0.1297)$ & 0.0935 & $(0.0113 ; 0.1230)$ & 0.1117 \\
\hline 29 & $(0.0000 ; 0.0459)$ & 0.0459 & $(0.0000 ; 0.0771)$ & 0.0771 \\
\hline
\end{tabular}

